\title{
FREE RADICAL SCAVENGING ACTIVITY OF SUGAR BEET (Beta Vulgaris L.) ROOT EXTRACTS
}

\author{
El-Dengawy, ${ }^{\star}$ R.A.H; Ferweez, ${ }^{\star *}$ H.M. and K.M. El-Hefnawy \\ * Food Industries Department, Faculty of Agricultural, Damietta \\ University, Egypt. ** Food science and Technology Department, \\ Faculty of Agricultural New Valley, Assiut University, Egypt.
}

\begin{abstract}
The ability of Beta Vulgaris L. roots to prevent the initiation of free radicals that cause cellular damage was investigated in vitro. The sugar beet roots were extracted exhaustively using methanol (SB) or extracted sugar beet pulp the residue left after sugar extraction - using methanol (SBP). In the reducing power assay, the more anti-oxidant compounds convert the oxidation form of iron $\left(\mathrm{Fe}^{+3}\right)$ in ferric chloride to ferrous $\left(\mathrm{Fe}^{+2}\right)$. The reducing power capacity of two extracts were found less than that of vitamin C. Total polyphenols capacity (TPC) and total flavonoids capacity (TFC) were evaluated according to Folin-Ciocalteu and aluminium chloride colorimetric assays, respectively. In this study, the SB extract has higher than SBP extract in TPC but lower in TFC. Radical scavenging activities of two extracts were tested against DPPH and SOD. (SB) and (SBP) methanolic showed a very low inhibition $(8.17 \%$ and $9.75 \%)$ comparing to Vitamin C. The maximum inhibition of SOD was $28.65 \%-34.97 \%$ at $1000 \mu \mathrm{g} / \mathrm{mL}$ for (SB) and (SBP) methanolic extracts, respectively.
\end{abstract}

\section{INTRODUCTION}

Free radicals are created when cells use oxygen to generate energy. These by-products are generally reactive oxygen species (ROS) such as superoxide anion, hydroxyl radical and hydrogen peroxide that result from the cellular redox process. At low or moderate concentrations, ROS exert beneficial effects on cellular responses and immune function but at high levels, free radicals and oxidants generate oxidative stress, a deleterious process that can damage cell structures, including lipids, proteins, and DNA (Pham-Huy et al., 2008). Oxidative stress plays a major part in the development of chronic and degenerative ailments such as cancer, autoimmune disorders, rheumatoid arthritis, cataract, aging, cardiovascular and neurodegenerative diseases, (Willcox et al., 2004). The human body has several mechanisms to counteract oxidative stress by producing antioxidants, which are either naturally produced in situ, or externally supplied through foods and/or supplements. These antioxidants act as free radical scavengers by preventing and repairing damages caused by ROS, and therefore can enhance the immune defense and lower 
the risk of cancer and degenerative diseases (Pham-Huy et al., 2008). In recent years, there is an increasing interest in finding antioxidant phytochemicals, because they can inhibit the propagation of free radical reactions, protect the human body from diseases. The most effective components seem to be flavonoids and phenolic compounds of many plant raw materials, particularly in herbs, seeds, and fruits. Their metal-chelating capabilities and radical- scavenging properties have enabled phenolic compounds to be as effective free radical scavengers and inhibitors of lipid peroxidation (Terao and Piskula, 1997).

Sugar beet (Beta vulgaris L.) is the world's most cultivated crop for sucrose production for human consumption after sugar cane (Saccharum officinarum L.). The beet root contains a high level of sucrose, which varies between $12 \%$ and $21 \%$ on the fresh weight (FW) basis, depending on cultivar and growing condition (Trebbi, 2005).

Sugar beet pulp (SBP) is a by-product from sugar industry after extraction and is mainly used for animal feeding (Michel et al., 1988). On a dry weight basis, SBP contains $75 \%-80 \%$ polysaccharides, consisting roughly of $22 \%-24 \%$ cellulose, $30 \%$ hemicelluloses, mainly arabinans and (arabino) galactans and $25 \%$ pectin. Small amounts of fat, protein, ash and lignin contents in SBP are 1.4\%, 10.3\%, 3.7\% and $5.9 \%$, respectively (Sun and Hughes, 1999).

We now report the present study on sugar beet root extracts to evaluate the phytochemical and antioxidant effect.

\section{MATERIAL AND METHODS}

\subsection{Sugar beet roots}

The roots of sugar beet (Beta vulgaris $L$ ) were collected from fields of Damietta in February 2014, washed and stored in a refrigerator at $4{ }^{\circ} \mathrm{C}$ till further use within two weeks.

\subsection{Extraction}

\subsubsection{Methanolic Extract of sugar beet (SB)}

The sugar beet roots were cut to slices and dried in a single layer at $60{ }^{\circ} \mathrm{C}$ in electric oven. The dried sample were powdered in a laboratory mill, $(60 \mathrm{~g})$ of dry sample were mixed with methyl alcohol $(1.0 \mathrm{~L}, 99.9 \%)$ in a closed flask and kept for 24 hours. Shaking frequently during the first 6 hours and allowed to stand for 18 hours. Thereafter, it was filtered rapidly taking precautions against the loss of the solvent. The methanolic extract was concentrated to dryness in a rotary evaporator under vacuum and controlled temperature $\left(45^{\circ} \mathrm{C}\right)$. The extract was stored in a refrigerator at $4{ }^{\circ} \mathrm{C}$ till further use (Harborne, 1998). 


\subsubsection{Methanolic extract of sugar beet pulp (SBP)}

Sugar beet pulp was dried at $60^{\circ} \mathrm{C}$ in electric oven. The dried sample was powdered in a laboratory mill, $(60 \mathrm{~g})$ of dried sample was mixed with methyl alcohol (1.0 L, 99.9\%) in a closed flask and kept for 24 hours then filtered. The filtrate was concentrated to dryness in a rotary evaporator under vacuum and controlled temperature $\left(45^{\circ} \mathrm{C}\right)$. The dried extract was stored in a refrigerator at $4^{\circ} \mathrm{C}$ till further use (Harborne, 1998).

\subsection{Phytochemical Screening}

Terpenes, tannins, flavonoids, saponins, resins and alkaloids were detected in methanolic extract according to the method described by Harborne (1998).

\subsection{Determination of total polyphenols capacity (TPC)}

Total polyphenols capacity was determined using Folin-Ciocalteu method according to (Li et al., 2007). The absorbance was measured at wavelength $750 \mathrm{~nm}$. Total phenol capacity was expressed as milligram gallic acid equivalent (GAE)/g extract.

\subsection{Determination of total flavonoids capacity (TFC)}

Aluminum chloride colorimetric method was used for quantitative flavonoids determination (Chang et al., 2002). The absorbance was measured at wavelength $415 \mathrm{~nm}$. Total flavonoid capacity was expressed as milligram quercetin equivalent (QE) / g extract.

\subsection{Antioxidant activity}

\subsubsection{Estimation of reducing power}

Reducing power assay was determined as described in the method of (Ferreira et al., 2007). Ascorbic acid was used as standard reference. Absorbance was measured at wavelength $700 \mathrm{~nm}$ against the corresponding blank solution.

\subsubsection{DPPH (2, 2 -diphenyl-1-picryl-hydrazyl) free radical scavenging activity}

DPPH radical scavenging capacity was determined according to the technique reported by (Martins et al., 2008). Sample solution was diluted with dimethyl sulfoxide (DMSO) and in each reaction mixture, the solution was mixed with $2.0 \mathrm{ml}$ of $100 \mu \mathrm{M} \mathrm{DPPH}$. The mixture was shaken vigorously and allowed to reach a steady state at room temperature for $30 \mathrm{~min}$. in dark. Decolorization of DPPH was determined by measuring the absorbance at wavelength $517 \mathrm{~nm}$. 


\subsubsection{Superoxide Dismutase Activity Assay}

Superoxide dismutase activity was assayed by the method of Dechatelet et al. (1974). The increase in absorbance was measured at wavelength $560 \mathrm{~nm}$ during $5 \mathrm{~min}$. The reading was taken in each minute and the change in the mean absorbance/min was then calculated.

\section{RESULTS AND DISCUSSION}

\subsection{Preliminary phytochemical screening of sugar beet extracts.}

The preliminary phytochemical screening reveals the presence of terpenes, tannins, flavonoids, saponins and alkaloids, however resins are not found in the sample. The results are shown in Table 1.

Table 1: Qualitative analysis of phytochemical constituents of SB and SBP extracts

\begin{tabular}{|c|c|c|}
\hline Constituent & SB Level ${ }^{*}$ & SBP Level ${ }^{* \star}$ \\
\hline Terpenes & + & + \\
\hline Tannins & $\begin{array}{l}T \\
+\end{array}$ & + \\
\hline Flavanoids & + & + \\
\hline Saponins & + & + \\
\hline Resins & - & - \\
\hline Alkaloids & + & + \\
\hline
\end{tabular}

\subsection{Quantitative Estimations}

Two different extracts were used in this study, since a wide range of extracts hold a better chance for the extraction and isolation of biologically active molecules for general screening of bioactivity.

Data in Table 2 showed that the lowest amount of total polyphenols capacity (TPC) was $7.32 \mu \mathrm{g} \mathrm{GAE} / \mathrm{g}$ extract in SBP extract while the highest was observed in SB extract with a value of $8.45 \mu \mathrm{g}$ $\mathrm{GAE} / \mathrm{g}$ extract. Phenols and polyphenolic compounds, such as flavonoids, are widely found in food products derived from plant sources, and they have been shown to possess important antioxidant activities (Nagavani et al., 2010). The high amount of phenols and flavonoids in extracts may explain their high antioxidative activities. Total flavonoids capacity (TFC) of the extracts were also determined using aluminum chloride assay, a widely adopted method in almost all published works to measure the total flavonoid content of plants. The principle of this colorimetric method is based on the acid-stable complex between aluminum chloride, and the participation of $\mathrm{C}-4$ keto 
group and either the C-3 or C-5 hydroxyl group shown in flavones and flavonols of structure below, (Chang et al., 2002).

Also from the same table, the SBP extract has the highest amounts of total flavonoid content (TFC) (1.868 mg QE/g extract), while the lowest amount (1.51 mg QE/g extract) was observed in SB methanolic extract. In this study, TPC and TFC can be further tested for methanolic extracts ability to inhibit different free radicals. Total phenolic and flavonoid contents for SB and SBP extracts are demonstrated in Table 2.

Table 2: Total polyphenolic and flavonoid capacities for Sugar beet extracts

\begin{tabular}{|c|c|c|}
\hline Extracts & $\begin{array}{c}\text { Total Polyphenols Capacity } \\
\text { (mg GAE/g) }^{\mathbf{a}}\end{array}$ & $\begin{array}{c}\text { Total Flavonoids Capacity } \\
\text { (mg QE/g) }^{\mathbf{b}}\end{array}$ \\
\hline $\mathbf{S B}^{*}$ & 8.45 & 1.51 \\
\hline $\mathbf{S B P}^{* *}$ & 7.32 & 1.868 \\
\hline
\end{tabular}

a (mg GAE/ g): $\mathrm{mg}$ of gallic acid equivalent per $\mathrm{g}$ of dry plant extract.

${ }^{b}(\mathrm{mg} \mathrm{QE} / \mathrm{g}): \mathrm{mg}$ of quercetin equivalent per $\mathrm{g}$ of dry plant extract.

* $\mathrm{SB}=$ Sugar beet extract.

** SBP= Sugar beet pulp extract.

\subsection{Reducing Power Assay}

Reducing power assay measures the total reducing capability of antioxidants on the basis of the methanolic extract or vitamin $\mathrm{C}$ ability to reduce $\mathrm{Fe}^{+3}$ to $\mathrm{Fe}^{+2}$ ions. This assay treats the antioxidants in the samples as reductants in a redox-linked colorimetric reaction and is relatively simple and easy procedure to be standardized. One possible disadvantage with this assay is the fact that this assay does not react fast with some antioxidants, such as glutathione. However, It is still suitable for assessment of antioxidant activity of extract because only limited amounts of plant glutathione are absorbed by humans (Schafer and Buettner, 2001). The reducing power capacity of SBP methanolic extract as $41.34 \mu \mathrm{g} \mathrm{VC} / \mathrm{ml}$, was higher than that of SBP methanolic extract $(40.55 \mu \mathrm{g} \mathrm{V} / \mathrm{ml})$ at $1000 \mu \mathrm{g} / \mathrm{ml}$ as shown in (Table 3).

Table 3: Reducing power capacity for different SB and SBP methanolic extracts concentrations

\begin{tabular}{|c|c|c|}
\hline \multirow{2}{*}{$\begin{array}{c}\text { Concentration } \\
(\boldsymbol{\mu} \mathbf{g} / \mathbf{m l})\end{array}$} & \multicolumn{2}{|c|}{ Reducing power capacity } \\
\cline { 2 - 3 } & $\mathbf{S B}^{\star}$ & $\mathbf{S B P}^{\star \star}$ \\
\hline 200 & 10.95 & 7.74 \\
\hline 400 & 18.35 & 16.14 \\
\hline 600 & 25.75 & 24.54 \\
\hline 800 & 33.15 & 32.94 \\
\hline 1000 & 40.55 & 41.34 \\
\hline
\end{tabular}

* $\mathrm{SB}=$ Sugar beet extract. 
** SBP $=$ Sugar beet pulp extract.

\subsection{DPPH assay}

There are various methods for determination of antioxidant activities. The measurement of radical scavenging activity of any antioxidant is commonly associated with the using of DPPH method because it is quick, reliable and reproducible method. It is widely used to test the ability of compounds as free radical scavengers or hydrogen donors and to evaluate the antioxidative activity of root extracts. The stable radical DPPH has maximum absorption at wavelength $517 \mathrm{~nm}$ and the antioxidant reduces it to the yellow colored diphenylpicrylhydrazine. Figure (1), as a typical example shows the effect of different concentrations of vitamin $\mathrm{C}$ on the electronic absorption spectra of DPPH dissolved in DMSO solvent. The concentration of antioxidant needed to decrease the initial DPPH concentration by $50 \%$ $\left(\mathrm{IC}_{50}\right)$ is a parameter widely used to measure the antioxidant activity. A lower $I_{50}$ value indicates a higher antioxidant power. Figure (2) shown the changes in DPPH radical scavenging activities according to different concentrations of sugar beet (SB) and sugar beet pulp (SBP) extracts. Both the SB and SBP extracts at concentration $10 \mathrm{mg} / \mathrm{mL}$ have the inhibition percentage of 8.17 and 9.75 , respectively. These inhibition values show a very weak DPPH radical scavenging. On the other hand, vitamin $\mathrm{C}$ gave the inhibition percentage of $50 \%\left(\mathrm{IC}_{50}\right)$ at $12.34 \mu \mathrm{g} / \mathrm{mL}$.

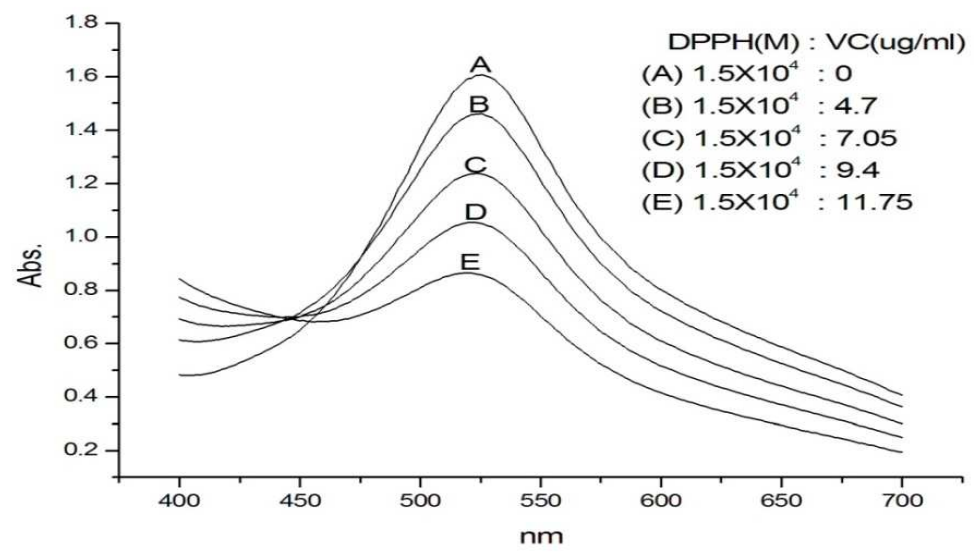

Figure 1: Effect of Vitamin C concentration on the UV-visible spectra of $\mathrm{DPPH}$ in DMSO solvent at $25^{\circ} \mathrm{C}$ 


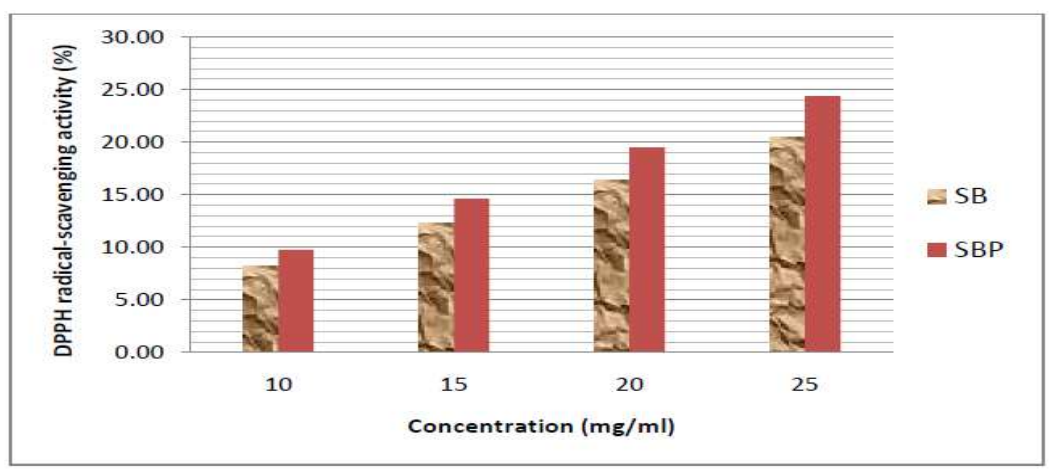

Figure 2: Changes in DPPH radical scavenging activities according to different concentrations of sugar beet (SB) and sugar beet pulp (SBP) extracts

\subsection{Superoxide Dismutase Activity Assay}

Superoxide anion plays an important role in plant tissues and is involved in the formation of other cell-damaging free radicals (Duan et al., 2007). It is an oxygen-centered radical with selective reactivity and precursor to active free radicals as hydrogen peroxide, hydroxyl radical and singlet oxygen that have ability to react with biological macromolecules and thereby inducing tissue damage (Wickens, 2001). The inhibition percent of superoxide anion radical generated at $1000 \mu \mathrm{g} / \mathrm{mL}$ concentration of SBP and SB methanolic extracts and the results in (Table 4) was found as $34.97 \%$ and $28.65 \%$ inhibition, respectively.

Table 4: Superoxide dismutase activity for different SB and SBP methanolic extracts concentrations

\begin{tabular}{|c|c|c|}
\hline Concentration $(\boldsymbol{\mu g} / \mathbf{m l})$ & \multicolumn{2}{|c|}{ Inhibition \% } \\
\cline { 2 - 3 } & $\mathbf{S B}^{*}$ & SBP $^{* \star}$ \\
\hline 250 & 12.30 & 19.15 \\
\hline 500 & 17.75 & 24.42 \\
\hline 750 & 23.20 & 29.70 \\
\hline 1000 & 28.65 & 34.97 \\
\hline
\end{tabular}

${ }^{*} \mathrm{SB}=$ Sugar beet extract.

** $\mathrm{SBP}=$ Sugar beet pulp extract.

\section{REFFERENCES}

Chang C.; M. Yang; H. Wen and J. Chern (2002). Estimation of total flavonoid content in propolis by two complementary colorimetric methods. J. Food Drug Analaysis, 10: 178-182.

Dechatelet, L.R.; C.E. McCall; L.C. McPhial and R.B. Johnson (1974). Spectrophotometric method for determination of superoxide dismutase enzyme in serum. J. Clin. Invest., 53: 1197 - 1202. 
Duan, Y.; R.A. Gross and S.S. Sheu (2007). $\mathrm{Ca}^{2+}$-dependent generation of mitochondrial reactive oxygen species serves as a signal for poly(ADP-ribose) polymerase-1 activation during glutamate excitotoxicity. J. Physiol., 585: $558-741$.

Ferreira, I.C.F.R.; P. Baptista; M. Vilas-Boas and L. Barros (2007). Freeradical scavenging capacity and reducing power of wild edible mushrooms from northeast Portugal: Individual cap and stipe activity. Food Chem., 100: 1511-1516.

Harborne J.B. (1998). Phytochemical Methods. A Guide to Modern Techniques of Plant Analysis. (3rd edition). Chapman and Hall Co., New York, 1-302.

Li, H.B.; K.W. Cheng; C.C. Wong; K.W. Fan; F. Chen and Y. Jiang (2007). Evaluation of antioxidant capacity and total phenolic content of different fractions of selected microalgae. Food Chem., 102: 771776.

Martins, F.T.; A.C. Doriguetto; T.C. de Souza; K.R.D. de Souza; M.H. dos Santos; M.E.C. Moreira, and L.C.A. Barbosa (2008). Composition, and anti-inflammatory and antioxidant activities of the volatile oil from the fruit peel of Garcinia brasiliensis. Chem. Biodivers., 5: 251-258.

Michel, F.; Thibault, J.F.; Barry, J.L. (1988) Preparation and characterisation of dietary fibre from sugar beet pulp. J Sci Food Agric.42:77-85.

Nagavani, V.; Y. Madhavi; D. Bhaskar Rao; P. Koteswara Rao and T. Raghava Rao (2010). Free radical scavenging activity and qualitative analysis of polyphenols by RP-HPLC in the flowers of Couroupita guianensis Abul. Electronic Journal of Environmental, Agricultural and Food Chemistry, 9: 1471-1484.

Pham-Huy, L.A.; H. He and C. Pham-Huyc (2008). Free Radicals, Antioxidants in Disease and Health. International Journal of Biomedical Science, 4(2): 89-96.

Schafer, F.Q. and G.R. Buettner (2001): Redox environment of the cell as viewed through the redox state of the glutathione disulfide/glutathione couple. Free Radic Biol Med., 30: 1191-1212.

Sun, R.C. and S. Hughes, (1999). Carbohydrate Polymers, 38: 273-281.

Terao, J. and M.K. Piskula (1997). Flavonoids as inhibitors of lipid peroxidation in membranes. In Rice- C.A. Evans and L. Packer (editor), Flavonoids in health and disease. Marcel Dekker. New York, pp.277-295.

Trebbi, D.(2005). Genetic Analysis of Sucrose Accumulation in Sugar Beet (Beta vulgaris L.). Unpublished Ph.D. Dissertation. Michigan State University, East Lansing, MI, USA.

Varadarajan P.; G. Rathinaswamy and D. Asirvatahm (2008). Antimicrobial properties and phytochemical constituents of Rheo discolor. Ethnobotanical Leaflet., 12: 841-845.

Wickens A.P. (2001): Aging and the free radical theory. Respiratory Physiology. 128: 379-391 
Willcox J.K.; S.L. Ash and G.L. Catignani (2004). Antioxidants and prevention of chronic disease. Critical Reviews in Food Science and Nutrition, 44: 275-295.

$$
\text { رزق أحمد حامد الانجاوى *، حسين فرويز محمد* الثوارد الحرة لمستخلصات من جذور بنجر السكر }
$$

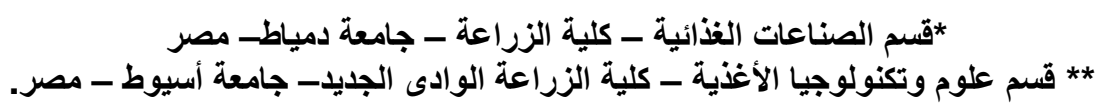

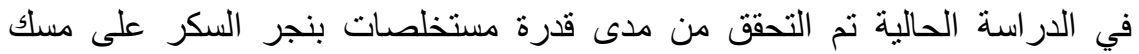

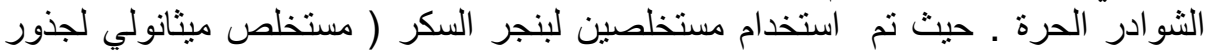

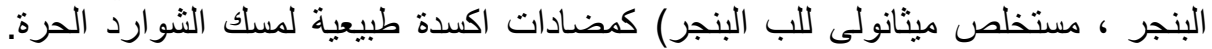

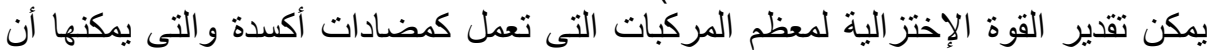

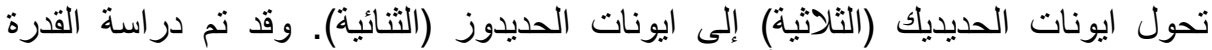

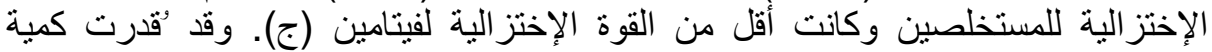

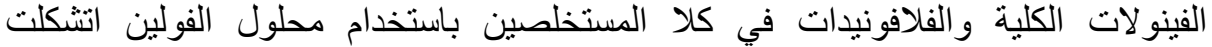

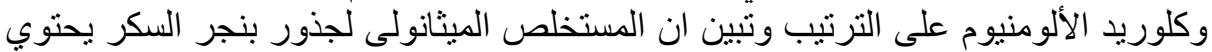

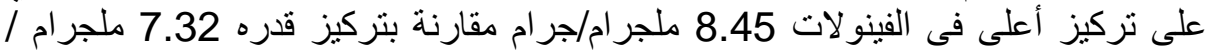

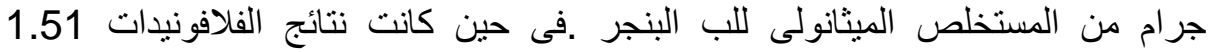

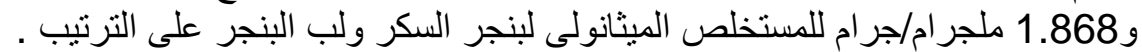

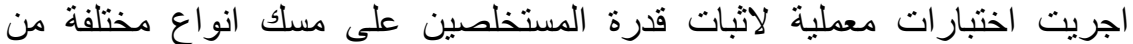

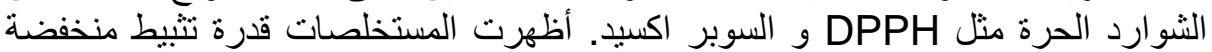

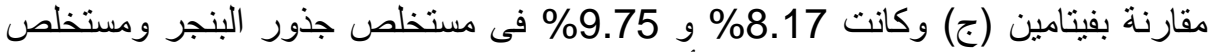

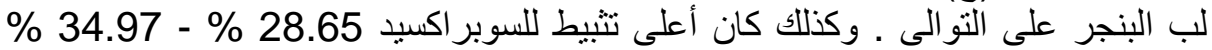

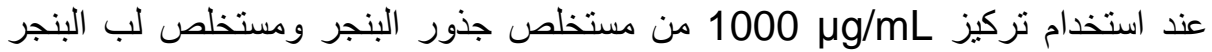

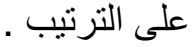

